\title{
The Relation Between Participation Motives and Goal Orientation of Participants in Recreational Dance Activities
}

\section{Dimitrios Goulimaris}

\author{
School of Physical Education \& Sport Science, Democritus University of Thrace, Greece \\ dgoulima@phyed.duth.gr
}

\section{Filippos Filippou}

School of Physical Education \& Sport Science, Democritus University of Thrace, Greece ffilippo@phyed.duth.gr

\author{
Doi:10.5901/mjss.2016.v7n3p302
}

\section{Abstract}

\begin{abstract}
The aim of the study was to investigate: a) the participation motives of adults who take part in recreational dance activities, b) whether their demographic characteristics differentiate their participation motives and goal orientation and c) the relation between motivation and goal orientation. The study sample was 908 adult men and women, who participated in learning Greek dances. For the data collection, the method used was the Greek version (Patsiaouras, Keramida \& Papanikolaou, 2004) of Participation Motivation Questionnaire (Gill, Gross \& Huddleston, 1983) and the Greek version (Diggelidis \& Papaioannou, 2002) of "Personal Orientation" questionnaire (TEOSQ: Task \& Ego Orientation in Sport Questionnaire) (Duda \& Whitehead, 1998). Considering the results of the research, the emerging conclusions are: a) the factors "fitness", "abilities-skills" and "friendship" constitute the most important motives for participating in dance activities. b) gender, age, educational level and dancing experience become partly differentiating factors for participation motives c. among the recreational dance activities, Greek dances form a natural activity in which the participants are both internally and externally motivated.
\end{abstract}

Keywords: motives, dance, goal orientation, dancing club

\section{Introduction}

The fifties is a decade of paramount importance for the Greek society and the Greek dance, since during these years the last traces of their traditional expression are lost. Dance loses its natural environment, which was the village square, and it is transferred to the city as a spectacle. The various entertainment restaurants and the dance association rooms are now the new spaces of presenting it (Filippou, 2015a).

The dance association rooms which are created by the internal migrants in their new places of settlement become the main spaces of presenting Greek dances. The function of dance as a commonly organized and executed activity changes, as it acquires a practical and educational character. The aim of a dance association is, mainly, the stage presentation of a dance, the emphasis given on learning its technique, a procedure which requires constant and tiresome effort (Filippou, 2014).

The educational dimension of dance became a topic of interest for the Departments of Physical Education and Sports, where a lot of studies were carried out concerning not only Physical Education (Dalakis, Yfantidou, Tsitskari, Costa, Matsouka \& Tzetzis, 2016; Tsitskari, Antoniadis \& Costa, 2014; Tsitskari, Tsiotras \& Tsiotras 2006; Vernadakis, Antoniou, Zetou \& Kioumourtzoglou, 2004; Vernadakis, Giannousi, Tsitskari, Antoniou \& Kioumourtzoglou, 2012; Voutsina \& Goulimaris, 2016) but also dance in general. In such studies, the students are specialized in Greek dance, approaching it from different angles (Alygizakis, 2005; Filippou \& Goulimaris, 2016; Goulimaris, 2015; Goulimaris, Koutsouba \& Giosos, 2008; Goulimaris, Mavridis, Genti \& Rokka, 2014; Lykesas, 2002; Tyrovola, 1994).

According to researches, students up to 15 years old and adults above 30 constitute the majority of those who participate in associations developing dance activities (Goulimaris, 1998). In the last years, there has been a significant increase in the turnout of adults in dance associations. This increased turnout serves these associations in multiple ways because on the one hand they prosper financially and on the other hand they have the human material which is vital for their survival. Also, this increased turnout, since the organizers desire to keep it on the same level, has become a topic of research, trying to investigate the reasons for participating in collective dance activities 


\section{Literature Review}

Researches which study the motives why young people participate in dance activities (Doulias, Kosmidou, Pavlogiannis \& Patsiaouras, 2005; Rokka, Mavridis, Mavridis, Kelepouris \& Filippou, 2015), or why adults participate in dance associations as a recreational activity (Papaioannidou, Basdeki \& Filippou, 2005; Zanou, Chasandra \& Goudas, 2001) show that the motives for the turnout of such people are connected to their need to reduce daily anxiety, to co-exist in a team, to be with friends and to exercise through dancing. There are also researches investigating participation motives in relation to foreigners who took up Greek dance lessons in Greece (Filippou, Goulimaris, Michaltsi \& Genti, 2010), Cyprus (Patsiaouras, Xatzigianis, \& Anagnostou, 2012) and France (Filippou, Kipourou, Goulimaris, Serbezis \& Genti, 2009). The results show that dance is an activity which the participants can aspire to many things from. Some of these things are to learn about the Greek civilization through dancing, to create new friendships, to get in touch with other people, to relieve their stress and finally to exercise.

Since childhood, people shape a Goal Orientation considering what is important for them. These goals can be altered within the frame of a steady orientation (Piaget, 1972). Goal Orientation can be distinguished into two opposing directions: The first one is directed towards learning/improving (task orientation) and the second one towards performing/achieving (ego orientation).

People who are interested in the kind of effort through which they will improve their skills are orientated towards learning, considering that trying is a factor to success (Duda, 1992). Participating in an activity is not related to their being good at it. They perceive their failure as a result of not trying enough and any mistakes are thought of as a chance to cover their insufficiencies (Bruner, 1985). They are cooperative and seek knowledge (Bandura, 1991).

People who are interested in how well they perform in a skill are orientated towards achieving. Their main concern is who are more skilled, comparing their performances to their personal one. They do not cooperate easily and they do not ask for help, because they believe it is an element of failure and inability. Their interest focuses on acquiring prestige, and they do not participate in making decisions during their learning. Finally, their basic preoccupation is to establish a worthy result (Duda, 1992; Nicholls, 1992).

\section{Aim of the Research}

The aim of this study was to investigate: a) the participation motives of adults who take part in recreational dance activities, b) whether their demographic characteristics differentiate participation motives and goal orientation and c) the relation between motivation and goal orientation.

\section{Methodology}

\subsection{Sample}

The study sample was 908 adult men and women of over 30 years of age. The participants were attending Greek dance courses in dancing associations. They were randomly chosen.

Table 1. Demographic characteristics of the sample

\begin{tabular}{lccclccc}
\hline Gender & $\%$ & Age & $\%$ & Education & $\%$ & Dancing Experience & $\%$ \\
\hline Men & 26,9 & $30-45$ & 45,5 & Elementary & 11,2 & 1 & 27,4 \\
Women & 73,1 & $46-60$ & 42,8 & High school & 53,3 & 2 & 12,9 \\
& & $60+$ & 11,7 & University & 35,5 & 3 & 26 \\
& & & & & & $4+$ & 33,7 \\
\hline
\end{tabular}

\subsection{Data collection}

For the data collection the method used was:

a. the Greek version (Patsiaouras, Keramida \& Papanikolaou, 2004) of Participation Motivation Questionnaire (Gill, Gross \& Huddleston, 1983). The questionnaire consists of 29 variables researching the eight parameters/factors of motivation. The first factor, "rejection of boredom and appearance" concerns the elimination of stress and daily preoccupations through their attendance and consists of five variables (e.g. I 
want to relax from daily stress). The second factor, "success/status" is related to the fact that they count on gaining recognition from the others and consists of four variables (e.g. I want to gain status and recognition). According to the third factor "challenge" the participants see the whole process as call for engagement in something that both pleases and entertains them and consists of four variables (e.g. It's pleasant and amusing). In the fourth factor "abilities-skills" the participants do not see their attendance simply as entertainment and escape from daily concerns, but through their long-lasting presence they aim at their dancing abilities improvement by learning new dances and consists of three variables (e.g. I wish to improve my dancing level). The fifth factor "fitness" expresses the chance for exercise and the maintenance or even improvement of their health and consists of four variables (e.g. I want to have a good physical fitness). The sixth factor "team" denotes the possibility of coexistence with other people who have the same interests with them and consists of three variables (e.g. I like team spirit). The seventh factor "friendship" is related to the possibility of being with their friends once and having a pleasant time and consists of three variables (e.g. want to make new friends). Finally, the eighth factor "popularity" concerns the participants who aspire to be popular and important by participating in an activity they are adept at and consists of three variables (e.g. I like feeling important).

b. The Greek version (Diggelidis \& Papaioannou, 2002) of "Personal Orientation" questionnaire (TEOSQ: Task \& Ego Orientation in Sport Questionnaire) (Duda \& Whitehead, 1998). The questionnaire consists of 13 variables divided in two factors. The first factor is called "task orientation", it tests whether the participants are orientated in learning and consists of seven variables e.g. "I learn a new dance and this makes me want to practice more". The second one is named "ego orientation" and investigates whether the participants are competitive and largely interested in their performance and prominence. This factor consists of six variables e.g. "The others "blow it" whereas I do not".

The answers were given in a five-point Likert type scale, where one (1) stood for "absolutely disagree" and five (5) for "absolutely agree".

\subsection{Measurement process}

The completion of questionnaire was anonymous and with the consent of participants. It was carried out in dance halls before or after the dance lessons. The completion time was around 15 minutes.

\section{Results}

\subsection{Reliability analysis}

The reliability control of the questionnaire was carried out by calculating the values of a Cronbach, for each factor separately. As appears in table 2, the values of the factors were satisfactory $(a>.70)$. The results are similar to other researches (Cecchini, Méndez \& Muñiz, 2002; Gill, Gross \& Huddleston, 1983; Park, 2005; Patsiaouras, Xatzigianis \& Anagnostou, 2012).

Table 2. Factors' Mean, Standard Deviation \& Cronbach's a

\begin{tabular}{lccc}
\hline Factor & M & SD & Cronbach's a \\
\hline Fitness & 4.7 & .40 & .87 \\
Abilities-skills & 4.3 & .81 & .92 \\
Friendship & 4.1 & .80 & .94 \\
Team & 3.7 & .63 & .89 \\
Rejection of boredom \& appearance & 3.5 & .77 & .97 \\
Success/status & 3.2 & .90 & .88 \\
Popularity & 2.0 & .36 & .72 \\
Challenge & 2.2 & .79 & .97 \\
Task orientation & 4.0 & .82 & .82 \\
Ego orientation & 2.0 & .83 & .83 \\
\hline
\end{tabular}




\subsection{Mean and standard deviation}

As it becomes evident in table 2, the factors "fitness" (M 4.7), "abilities-skills" (M 4.3), and "friendship" (M 4.1) are experienced with the most considerable tension followed by "team" (M 3.7) and "rejection of boredom and appearance" (M 3.5). The factor "challenge" (M 2.2) and popularity (M 2.0) showed the lowest value. As table 2 shows, the "task orientation" factor is experienced by the sample to a greater degree (M 4.0) in comparison with the "ego orientation" factor (M 2.0).

\subsection{Differences according to gender}

To ascertain any differences due to gender, a number of T-tests were carried out, on independent samples. The results show that gender can become a differentiating agent, for the factors:

a. "rejection of boredom and appearance" $t(906)=3.85, p<.05$. Men presented a statistically higher score (M 3.7 \& $\mathrm{SD} .79)$ than women (M $3.4 \& \mathrm{SD} .76)$.

b. "ego orientation" $t_{(906)}=3.89, p<.05$ : men presented a statistically higher score (M 2.2 \& SD 1.02) regarding the factor "ego orientation" in relation to women (M 1.9 \& SD .73).

\subsection{Differences according to age}

One-way analysis of variance was conducted to indicate any differences in age of the sample. Results revealed significant statistical differences only for the factor "abilities-skills" $F(2,905)=5.18, p<.05$ : those with age $60+$ presented a statistically higher score (M 4.6 \& SD .82) than aged 30-45 (M 4.2 \& SD .77) and 46-60 (M 4.3 \& SD .83).

\subsection{Differences according to educational level}

One-way analysis of variance was conducted to indicate any differences in "educational level" of the sample. Results revealed significant statistical differences for the factors:

a. "abilities-skills" $F(2,905)=3.55, p<.05$ : the high school graduates presented a statistically higher score (M 4.5 \& SD .79) than university graduates (M $4.2 \&$ SD .81).

b. "task orientation" $F_{(2,905)}=3.66, p<.05$ : the elementary school presented a statistically higher score (M $4.1 \&$ SD .86) than university graduates (M $3.9 \&$ SD .80 ).

\subsection{Differences according to dancing experience}

One-way analysis of variance was conducted to indicate any differences in "dancing experience" of the sample. Results revealed significant statistical differences only for the factor "abilities-skills" $F_{(3,904)}=4.48, p<.05$ : those with one year dancing experience presented a statistically higher score (M 4.4 \& SD .77) than with 4+ years dancing experience (M 4.2 $\&$ SD .82).

\subsection{Correlation analysis}

To examine the relation between the factors of Motivation and Goal Orientation, the correlation coefficient Pearson ( $r$ ) was calculated. The results show a statistically significant, positive correlation for the factors fitness and ego orientation ( $r$ $.31, p<.01)$ and a statistically significant, negative correlation for the factors popularity and task orientation $(r-.27, p<.01)$.

Table 3. Correlations between the factors of Motivation and Goal Orientation

\begin{tabular}{ccccccccc}
\hline \multicolumn{10}{c}{ Correlations } \\
\hline Task & Fitness & Skills & Friendship & Team & Rejection of Boredom & Success & Popularity & Challenge \\
Ego & .016 & .053 & .064 & .022 & -.029 & .068 & $-.274^{* *}$ & -.12 \\
${ }^{*} \mathrm{p}<.05,{ }^{* *} \mathrm{p}<.01$ & -.040 & .012 & -.020 & -.036 & .056 & -.061 & -.032 \\
\hline
\end{tabular}




\section{Conclusion}

The aim of the study was to investigate: a) the participation motives of adults who take part in recreational dance activities, b) whether their demographic characteristics differentiate their participation motives and goal orientation and c) the relation between motivation and goal orientation.

Once more, it seems that men do not participate equally with women in the dance activities organized by the various cultural associations (Doulias, Kosmidou, Pavlogiannis \& Patsiaouras, 2005; Filippou, Goulimaris, Michaltsi \& Genti, 2010 ; Papaioannidou, Basdeki \& Filippou, 2005; Patsiaouras, Xatzigianis \& Anagnostou, 2012; Zanou, Chasandra $\&$ Goudas, 2001). Men are a minority in opposition to women who impose their presence. It seems that this steadfast situation is due to a certain perception of western origin, that dancing is indicative for women rather than men. This is a mistaken opinion since Greek dance requires from a man not only to participate in dancing activities but also to acquire various dancing skills which he must exhibit given the chance. Furthermore, during dance man showed his masculinity, his manly stature and thus became an eligible bridegroom (Pitsi \& Filippou, 2014).

The results of the research make obvious that people who participate in recreational dance activities have a lot to aspire to. Participants expect to preserve their health on good levels or even to improve it, since they consider dancing as a form of exercising, to meet with friends and make new ones, to feel members of a team sharing the same interests and simultaneously to improve their dancing skills.

Heitmann (1986) claims that factors such as "friendship", "team" and "rejection of boredom" operate as internal motivation for action, since people participate in an activity for its own sake and the pleasure of learning something new. On the contrary, factors such as "fitness", "success" and "popularity" operate as external motivation to participate in physical activities, since people hope to gain something from this participation (Bebetsos, 2015a; Bebetsos \& Goulimaris, 2014).

These results indicated that dancing activities combine internal and external motivation. On the one hand, the participants are motivated internally since they want to meet with friends and make new ones, as well as feel members of a team sharing the same interests and on the other hand, they want to preserve their health on good levels. The results of the research are in accordance with other researches (Filippou, 2015b; Papaioannidou, Derri \& Filippou, 2015).

As concerns gender, men are more orientated to "ego" in relation to women. This is rather natural, since men are more competitive than women (Bebetsos, 2015b; Bebetsos \& Antoniou, 2012; Bebetsos \& Theodorakis, 2003; Bebetsos, Zouboulias, Antoniou, \& Kourtesis, 2013; Kouli, Bebetsos, Kamperis, \& Papaioannou, 2010). Contrary to the expected, the results of the factor "rejection of boredom/appearance" show that men have a higher percentage of participation than women. Women, according to Bebetsos, Zetou, and Antoniou (2014) participate in physical activities such as dancing, motivated on a higher degree than men by social factors connected to the body. This may result from the existing social reality in Greece, where a big percentage of men who lose their jobs spend many hours at home. The results of this research are in accordance with other researches (Filippou, 2015b; Papaioannidou, Derri \& Filippou, 2015) while they are opposite to the results found by Patsiaouras, Xatzigianis, and Anagnostou (2012) according to which, gender is not a differentiating factor in relation to motives for participating in dance activities.

According to the results, age is a differentiating agent only for the factor "abilities-skills". The older ones $(60+)$ desire on a higher degree to improve their dancing skills than those aged between 30-45 and 46-60.

The educational level of the participants is a differentiating agent for the factors "abilities-skills", and "task orientation". High school graduates participate on a higher degree to improve their dancing skills than university graduates. In addition, elementary education graduates are more "task" orientated than university graduates. This can be attributed to the fact that university graduates perceive their participating in dance activities less competitively, emphasizing more on the recreational part. In other words, they consider their participation less as a chance to improve their dancing skills, in opposition to the participants with primary or secondary education, and more as a chance to entertain.

Finally, dance experience becomes a differentiating agent only to the factor "abilities-skills" where those who have one year of experience are more interested in improving their dancing skills than those who have more than four years of dance experience. This is rather natural, since those with short experience have not yet developed their dance skills adequately, while those with longer experience consider that they have fully developed their dancing abilities.

One of the aims of this research was to investigate the relation between the factors of Motivation and Goal Orientation. Although the occurring correlations are from low to moderate, it seems that there is a reverse relation between the factors "Task Orientation" and "Popularity". At the same time, the more the factor "Ego Orientation" increases, the more the factor "Fitness" improves, which means that the more people are interested in their physical condition, the more they are orientated in their ego. This fact reinforces the opinion that participants are both internally 
and externally motivated.

Considering the results of the research and the following discussion the occurring conclusions are:

a. The factors "fitness", "abilities-skills" and "friendship" are the strongest motives so as to participate in dance activities.

b. Gender, age, educational level and dancing experience are partly differentiating factors for the participation motives.

c. Recreational dance activities such as Greek dance are physical activities in which the participants are both internally and externally motivated.

\section{References}

Alygizakis, A. (2005). Cretan dance. Art and physical exercise. Heraklion: Seistron.

Bandura, A. (1991). Human agency: The Rhetoric and the Reality. American Psychologist, 2, 157-162.

Bebetsos, E. (2015a). Psychological skills of elite archery athletes. Journal of Human Sport \& Exercise, 10 (2), 623-628.

Bebetsos, E. (2015b). Prediction of Participation of Undergraduate University Students in a Music and Dance Master's Degree Program. International Journal of Instruction, 8 (2), 165-176.

Bebetsos, E., \& Antoniou, P. (2012). Competitive state anxiety and gender differences among youth Greek badminton players. Journal of Physical Education and Sport, 12 (1), 107-110.

Bebetsos, E., \& Goulimaris, D. (2014). Personal outcome and leadership as defining factors of satisfaction in the context of the course "Arts II: Overview of Greek Music and Dance" of the Hellenic Open University. Turkish Online Journal of Distant Education, 15 (2), 12-23.

Bebetsos, E., \& Theodorakis, N. (2003). Athletes' Satisfaction Among Team Handball Players in Greece. Perceptual and Motor Skills, 97, 1203-1208.

Bebetsos, E., Zetou, E., \& Antoniou, P. (2014) How does parental motivational climate differentiate athletic experience? Journal of Physical Education and Sport, 14 (4), 526-531.

Bebetsos, E., Zouboulias, S., Antoniou, P., \& Kourtesis, T. (2013). Do anxiety, anger and aggression differentiate elite water-polo players? Journal of Physical Education and Sport, 13 (2), 209-212.

Bruner, J. (1985). Models of the Learner. Educational Researcher. 14(6), 5-8.

Cecchini, J., Méndez, A. \& Muñiz, J. (2002). Motives for practicing sport in Spanish schoolchildren. Psicothema. 14(3), 523-531.

Dalakis, A., Yfantidou, G., Tsitskari, E., Costa, G., Matsouka, O. \& Tzetzis, G. (2016). The location and activities that eco tourists prefer in Greece. The case of Eastern Macedonia \& Thrace. Journal of Physical Education and Sport, 16, in press.

Diggelidis, N. \& Papaioannou, A. (2002). Interaction between effort, entertainment, personal orientation and perception of prompting in Physical Education lessons. Sports Psychology, 13, 35-55.

Doulias, E., Kosmidou, O., Pavlogiannis, O. \& Patsiaouras, A. (2005). Investigation of teenagers' participation motives in groups of traditional dance. Hape. 3, 2, 107-112.

Duda, J.L. (1992). Motivation in sport settings: A goal perspectives approach. In G.C. Roberts (Ed.), Motivation in Sport and Exercise (pp. 57-91). Champaign, IL: Human Kinetics.

Duda, J.L., \& Whitehead, J. (1998). Measurement of goal perspectives in the physical domain. In J.L. Duda (Ed.), Advances in sport and exercise psychology measurement (pp. 21- 48). Morgantown, WV: Fitness Information Technology.

Filippou, F. (2014). The role of the kinetic motif in determining the form and time of dance through the dance "Tis Marias". Journal of Physical Education and Sport. 1 (18), 115-119.

Filippou, F. (2015a). The first woman's dancer improvisation in the area of Roumlouki (Alexandria) through the dance "Tis Marias". Ethnologia, 6(b), 1-24.

Filippou, F. (2015b). The effect of an interdisciplinary Greek traditional dance, history, and anthropology program on male and female students' achievement goal orientations. Journal of Physical Education and Sport, 15(3), 610 - 614.

Filippou, F., Goulimaris, D., Michaltsi, M., \& Genti, M. (2010). Dance and cultural tourism: The effect of demographic characteristics on foreigners' participation attendance in traditional Greek dancing courses. Studies in Physical Culture and Tourism. 1, 63-71.

Filippou, F. \& Goulimaris, D. (2016) How motivational climate is differentiated among adult dancers, within an educational context? Journal of Physical Education and Sport, 16, 1, in press.

Filippou, F., Kipourou, P., Goulimaris, D., Serbezis, V., \& Genti, M. (2009). Participation motives of French in Traditional Greek Dance Teaching Seminars Organized in France. International Journal of Sport Management, Recreation \& Tourism. 4(d), 52-59.

Gill, D. L., Gross, J.B., \& Huddleston, S. (1983). Participation motivation in youth sports. International Journal of Sport Psychology, 14, 114.

Goulimaris D. (2015). The relation between distance education students' motivation and satisfaction. Turkish Online Journal of Distance Education, 16, 2.

Goulimaris, D. (1998). Study of the organizational structure and functioning of traditional dance organizations in Greece and Belgium. The European dimension (in Greek). .Unpublished doctoral dissertation, Komotini, Democritus University of Thrace, Greece.

Goulimaris, D., Koutsouba, M., \& Giosos, Y. (2008). The organization of a distance postgraduate dance program and the participation of students specializing in dance. Turkish Online Journal of Distance Education, 9(3), 59-73. 
Goulimaris, D., Mavridis, G., Genti, M. \& Rokka S. (2014). Relationships between basic psychological needs and psychological wellbeing in recreational dance activities. Journal of Physical Education and Sport, 14, 2, 277-284.

Heitmann, H.H. (1986). Motives of older adults for participating in physical activity programs. In McPherson, B. (Ed.), Sport and aging (pp 199-204). Champaign, IL: Human Kinetics.

Kouli O., Bebetsos E., Kamperis I., \& Papaioannou A. (2010). The relationship between emotions and confidence, among competitive sports. Kinesiology, 42 (2), 194-200.

Lykesas, G. (2002). The teaching of Greek traditional dances in primary education by the musical education method (in Greek). Unpublished doctoral dissertation, Aristotle University of Thessaloniki, Greece.

Nicholls, J. (1992). The general and the specific in the development and expression of achievement motivation. In: G. Roberts (Ed.), Motivation in sport and exercise, (pp. 31-56). Champaign, IL: Human Kinetics.

Papaioannidou, M., Basdeki, N. \& Filippou, F. (2005). Participation motives of adults

in dance activities. Sport \& Society. 36, 69.

Papaioannidou, M., Derri, V., Filippou, F. (2015). The effect of an interdisciplinary Greek traditional dance, history, and geography program on elementary students' satisfaction and motivation. Sport Science. 8(2), 83-90.

Park, S. R. (2005). A cross-cultural study of the motivational factors affecting individuals' decision about participating in action sports between Korean college students and their American counterparts. International Journal of Eastern Sports \& Physical Education, 3(1), 3-27.

Patsiaouras, A., Keramida, P. \& Papanikolaou, Z. (2004). Adjustment of motivation

questionnaire in order to participate Greeks people in sport activities. 3rd International Congress of Sport Psychology, Trikala, Greece.

Patsiaouras, A., Xatzigianis, E. \& Anagnostou, E. (2012). Reason for participation in traditional Cypriot Dances. Facta Universitatis. 10(1), $39-48$.

Piaget, J. (1972). Epistémologie des sciences de l'homme. Paris: Gallimard.

Pitsi, A., \& Filippou, F. (2014). Dancing and music in symbiotic groups: the example of the Vlahs-Armani of Seli Imathias-Greece. Journal of Physical Education and Sport, 14(2), $205-210$.

Rokka, St., Mavridis, G., Mavridis, Z., Kelepouris, A., Filippou, D.A. (2015). Traditional Dance as Recreational Activity: Teenagers' motives participation. Sport Science 8(2), 76-82.

Tsitskari, E., Antoniadis, CH. \& Costa, G. (2014). Investigating the relationship among service quality, customer satisfaction and psychological commitment in Cyprian fitness centers. Journal of Physical Education and Sport, 14, 4, 79, $514-520$.

Tsitskari E., Tsiotras D. \& Tsiotras G. (2006). Measuring service quality in sport services. Total Quality Management \& Business Excellence, 17 (5), 623-631

Tyrovola, V. (1994). O "choros sta tria": Structural morphological and typological approach of the form (in Greek). Unpublished doctoral dissertation, National and Kapodistrian University of Athens, Greece.

Vernadakis, N., Antoniou, P., Zetou, E., Kioumourtzoglou, E. (2004). Comparison of three different instructional methods on teaching the skill of shooting in basketball. Journal of Human Movement Studies, 46(5), 421-440.

Vernadakis, N., Giannousi, M., Tsitskari, E., Antoniou, P., \& Kioumourtzoglou, E. (2012). A comparison of student satisfaction between traditional and blended technology course offerings in physical education. Turkish Online Journal of Distance Education, 13(1), 137-147.

Voutsina, M. \& Goulimaris, D. (2016). Motivation and job satisfaction of people working in recreational dance activities. Sport Science, in press.

Zanou, S., Hassandra, M., \& Goudas, M. (2001). Researching of participation reasons of people in recreational physical activities. Qualitative study in people participating in traditional dance groups. Sport Psychology, 12, 61-72. 